\title{
The Effect of Perceived Self-Esteem and Mental Health of Nursing Students on Life Satisfaction
}

\author{
Geum Sook $\mathrm{Oh}^{1}$, Gwang Soo $\mathrm{Oh}^{2}$ \\ 1 Chungbuk Health Science University, Republic of Korea, \\ 2 Chodang University, Republic of Korea,
}

\begin{abstract}
This research studies correlation between perceived self-esteem, mental health, and life satisfaction of nursing students, and is conducted to examine how perceived self-esteem and mental health affect life satisfaction. Our subject was 195 students attending C college and $C$ college in $C$ area, and it was descriptive study. From May, $28^{\text {th }} 2018$ to June, $1^{\text {st }} 2018$, survey was distributed to collect data. As a result of multiple regression analysis, influence factors of nursing student's life satisfaction were motivation of $\operatorname{admission}(\beta=.266$, $p=.000)$ and perceived $\operatorname{self}-\operatorname{esteem}(\beta=.320, p=.000)$ as in order, and this variables explained life satisfaction $11.9 \%$. For nursing student's to be capable of using positive coping strategy in further promoting life satisfaction, We should consider student's motivation of admission and perceived self-esteem factors.
\end{abstract}

Keywords: Perceived Self-Esteem, Mental Health, Life Satisfaction, Nursing Students, Stepwise Multiple Regression.

\section{INTRODUCTION}

\subsection{Needs of study}

Criteria to assess the level of life satisfaction is determined by how individual or group members subjectively perceive their objective conditions from their important elements of life.[1] Therefore it's a process of individual assessing quality of life by comparing reality with their criteria, id est how each individuals positively assesses their life.[2] Selfesteem signifies the level of self-respect with positive, negative attitude toward ego I.e. as one and special object, and the level of reckoning self as a valuable person.[3] Recently, mental health is becoming a major issue in educational field. Especially college years as an adolescent stage when ego-identity forms, are within most sensitive period when values change. For this reason, this issue becomes critical, and is more serious for the nursing college students whom suffer from anxiety and severe stress related to clinical practice. [5] Self-esteem which is a personal resource affecting life satisfaction level, represents level of individual's ability to make oneself compatible and valuable. Thus higher self-esteem even enables one to consider hardship into opportunity [6]. Therefore perceived selfesteem and type of mental health affect life satisfaction of nursing college students. To this date, life satisfaction study conducted on college student showed that higher self-esteem is related to better adaptation to school life, and higher level of life satisfaction.[7-10] And also many domestic and international studies usually deal with stress, mental health, career, college service, or studies based on programs.
Likewise, in previous studies, self-esteem, life satisfaction or mental health acted as an independent variable or parameter. This study has its significance because influencing factor studies setting life satisfaction level as a direct subordinate variable are scarce.

Hence this study interprets effects of nursing student's life satisfaction according to their perceived mental health type, thereby provide fundamental data to help school life guidance to promote not only the nursing student's mental health and self-esteem but also their life satisfaction.

\subsection{Purpose of study}

Specific purpose of this studies are as followed;

1) Understand general characteristics of Nursing Students.

2) Understand mental health, self-esteem, and life satisfaction level of Nursing Students.

3) Distinguish differences in related variables considering nursing student's general characteristics.

4) Understand correlations between nursing student's life satisfaction related variables.

5) Understand influencive factors affecting nursing student's life satisfaction.

\section{MATERIAL AND METHODS}

\subsection{Subjects of study and data collection method}

Subjects of this study are 195 nursing college's student whom understand the purpose of this study and consented in written form, and are attending $\mathrm{C}$ University and $\mathrm{C}$ University located in $\mathrm{C}$ area, selected by random sampling method. Rather assessed using $\mathrm{G}^{*}$ power program, for the regression analysis of effect size 0.15 , significance level 0.05 , experiment examination $0.85,128$ subjects were calculated to be requiring.

\subsection{Tools of study}

Perceived Self-esteem: The self-esteem scale developed by Rosenberg in 1965[3] and later translated by Jeon[11] was used as a tool. Jeon[11]'s study calculated reliability coefficient be Cronbach's $\alpha=.79$, whereas this study showed Cronbach's $\alpha=.84$.

Mental Health: A tool of Psychosocial Wellbeing Index-Short Form(PWI-SF) developed by Chang et al.[12] was used. The higher the score means the poorer psychosocial wellbeing. In Chang et al.[12]'s study, credibility was Cronbach's $\alpha=.90$, This study showed Cronbach's $\alpha=.84$.

Life Satisfaction: The life satisfaction scale developed by Diener Fmmons, Larsen \& Griffin in 1985[13] and later used by Shim[14] was used as a tool. Shim[14]'s study conducted on college student's showed Cronbach's $\alpha=.82$. This study showed Cronbach's $\alpha=.84$. 


\subsection{Data collection}

Analysis data was collected from May $28^{\text {th }}$ to June $1^{\text {st }}, 2018$. Total 250 surveys were distributed and 232 returned. Within survey, 33 incomplete surveys were excluded and 195 copies were used for final data analysis.

\subsection{Data analysis}

Collected data was analyzed with SPSS Win 20.0. Average and standard deviation of mental health, self-esteem, and life satisfaction level was examined. Pearson's Correlation Coefficient was used to examine the relationship between
Nursing student's mental health, self-esteem, and life satisfaction level. Stepwise Multiple Regression were used to identify influence factor of nursing student's life satisfaction.

\section{RESULTS}

3.1. The general characteristics of the subjects

Subject of this study is 195 fresh year nursing student, which are 50 male students(25.6\%), 145 female students(74.4\%), female student outnumbered, major age group is 20s being $135(69.2 \%)$, admission motives to nursing college was mostly about employment being 105(53.8\%) [Table1].

[Table1] The General Characteristics $(\mathrm{N}=195)$

\begin{tabular}{|c|c|c|c|}
\hline Classification & Categories & $\mathbf{N}$ & $\%$ \\
\hline \multirow{2}{*}{ Sex } & Male & 50 & 25.6 \\
\hline & Female & 145 & 74.4 \\
\hline \multirow{2}{*}{ Age } & under 20 & 135 & 69.2 \\
\hline & Over 20 & 60 & 30.8 \\
\hline \multirow{4}{*}{ Religion } & Christianity & 127 & 65.1 \\
\hline & Buddhism & 47 & 24.1 \\
\hline & Catholic & 18 & 9.2 \\
\hline & Others & 3 & 1.5 \\
\hline \multirow{4}{*}{ Admission motives } & Employment & 105 & 53.8 \\
\hline & Recommendation & 18 & 9.2 \\
\hline & Realize Humanity & 30 & 15.4 \\
\hline & Others & 42 & 21.5 \\
\hline \multirow{2}{*}{ Major in other field more than 1year } & Yes & 40 & 24.1 \\
\hline & No & 148 & 75.9 \\
\hline \multirow{3}{*}{ Regular exercise } & Yes & 52 & 26.7 \\
\hline & No & 129 & 66.2 \\
\hline & Sometimes & 14 & 7.2 \\
\hline \multirow{3}{*}{ Regular diet } & Yes & 41 & 21.0 \\
\hline & No & 151 & 77.4 \\
\hline & Sometimes & 3 & 1.5 \\
\hline \multirow{3}{*}{ Economic level } & High & 21 & 10.8 \\
\hline & Medium & 156 & 80.0 \\
\hline & Low & 18 & 9.2 \\
\hline
\end{tabular}

\subsection{Extents of perceived self-esteem, mental health, life satisfaction of nursing student's}

Self-esteem scored average $33.20 \pm 4.89$ out of score range 26 to 48 . Mental health scored average $48.66 \pm 9.04$ out of score range 47 to 65 , Life satisfaction scored $23.18 \pm 5.53$ out of score range 27 to 35 [Table2].

[Table2] Subject's score of self-esteem, mental health and life satisfaction $(\mathrm{N}=195)$

\begin{tabular}{|l|l|l|l|}
\hline Variables & Range & Mean \pm SD & Min-Max \\
\hline Perceived Self-esteem & $26-48$ & $33.20 \pm 4.89$ & $22-48$ \\
\hline Mental Health & $47-65$ & $48.66 \pm 9.04$ & $18-65$ \\
\hline Life Satisfaction & $27-35$ & $23.18 \pm 5.53$ & $8-35$ \\
\hline
\end{tabular}

3.3. Difference between perceived self-esteem, mental health, life satisfaction according to nursing student's general characteristic:

As a result of analyzing variable differences according to general characteristics, mental health shows significant difference in regular excercise $(\mathrm{F}=3.082, p=.05)$, self-esteem shows significant difference in religion( $\mathrm{F}=2.657, p<.05)$. Level of life satisfaction showed significant differences in admission motive $(\mathrm{F}=6.218, p=.001)$. 
[Table3] Difference of perceived self-esteem, mental health, life satisfaction of nursing student's general characteristics( $\mathrm{N}=195)$

\begin{tabular}{|c|c|c|c|c|c|c|c|}
\hline \multirow{2}{*}{$\begin{array}{l}\text { Characteristi } \\
\text { cs }\end{array}$} & \multirow{2}{*}{ Categories } & \multicolumn{2}{|c|}{ Mental Health } & \multicolumn{2}{|l|}{$\begin{array}{l}\text { Perceived } \\
\text { Self-Esteem }\end{array}$} & \multicolumn{2}{|c|}{ Life Satisfaction } \\
\hline & & $\mathrm{M} \pm \mathrm{SD}$ & $\mathrm{t}$ or $\mathrm{F}(p)$ & $\mathrm{M} \pm \mathrm{SD}$ & $\mathrm{t}$ or $\mathrm{F}(p)$ & $\mathrm{M} \pm \mathrm{SD}$ & $\mathrm{t}$ or $\mathrm{F}(p)$ \\
\hline \multirow[t]{2}{*}{ Sex } & Male & $50.52 \pm 8.91$ & $\begin{array}{l}2.849 \\
(.093)\end{array}$ & $33.64 \pm 5.18$ & $\begin{array}{l}.543 \\
(.462)\end{array}$ & $24.36 \pm 5.781$ & $\begin{array}{l}3.034 \\
(.083)\end{array}$ \\
\hline & Female & $48.02 \pm 9.03$ & & $33.04 \pm 4.79$ & & $22.78 \pm 5.41$ & \\
\hline \multirow[t]{2}{*}{ Age } & Under20 & $49.25 \pm 8.89$ & $\begin{array}{l}.717 \\
(.543)\end{array}$ & $32.71 \pm 4.56$ & $\begin{array}{l}2.544 \\
(.057)\end{array}$ & $23.35 \pm 5.10$ & $\begin{array}{l}2.424 \\
(.067)\end{array}$ \\
\hline & Over 20 & $47.10 \pm 8.45$ & & $33.81 \pm 5.30$ & & $21.52 \pm 7.16$ & \\
\hline \multirow{5}{*}{ Religion } & Christianity & $48.43 \pm 8.45$ & $\begin{array}{l}.654 \\
(.581)\end{array}$ & $32.66 \pm 4.72$ & $\begin{array}{l}2.657 \\
(.050)\end{array}$ & $22.83 \pm 5.32$ & $\begin{array}{l}1.016 \\
(.387)\end{array}$ \\
\hline & Buddhism & $48.38 \pm 11.30$ & & $34.05 \pm 5.06$ & & $24.22 \pm 5.28$ & \\
\hline & Catholic & $49.76 \pm 9.39$ & & $33.91 \pm 4.69$ & & $23.95 \pm 6.18$ & \\
\hline & Others & $43.00 \pm 15.62$ & & $39.33 \pm 9.60$ & & $20.00 \pm 5.00$ & \\
\hline & Employment & $48.37 \pm 8.66$ & $\begin{array}{l}.389 \\
(.761)\end{array}$ & $33.07 \pm 4.79$ & $\begin{array}{l}2.228 \\
(.086)\end{array}$ & $21.84 \pm 5.26$ & $\begin{array}{l}6.218 \\
(.000)\end{array}$ \\
\hline \multirow{3}{*}{$\begin{array}{l}\text { Admission } \\
\text { motive }\end{array}$} & Recommendation & $50.83 \pm 7.31$ & & $30.83 \pm 3.82$ & & $22.77 \pm 7.24$ & \\
\hline & $\begin{array}{l}\text { Realize } \\
\text { Humanity }\end{array}$ & $48.36 \pm 9.78$ & & $33.50 \pm 4.42$ & & $24.46 \pm 5.15$ & \\
\hline & Others & $48.69 \pm 10.22$ & & $34.30 \pm 5.58$ & & $25.80 \pm 4.61$ & \\
\hline \multirow{3}{*}{$\begin{array}{l}\text { Major in } \\
\text { other } \\
\text { field more } \\
\text { than } \\
\text { 1year }\end{array}$} & Yes & $48.25 \pm 9.34$ & $\begin{array}{l}.127 \\
(.721)\end{array}$ & $34.25 \pm 4.70$ & $\begin{array}{l}2.912 \\
(.090)\end{array}$ & $24.08 \pm 5.62$ & $\begin{array}{l}1.624 \\
(.204)\end{array}$ \\
\hline & No & $48.79 \pm 8.97$ & & $32.86 \pm 4.91$ & & $22.90 \pm 5.49$ & \\
\hline & Yes & $47.23 \pm 10.84$ & $\begin{array}{l}3.082 \\
(.048)\end{array}$ & $34.25 \pm 5.33$ & $\begin{array}{l}2.439 \\
(.090)\end{array}$ & $24.26 \pm 5.30$ & $\begin{array}{l}1.365 \\
(.258)\end{array}$ \\
\hline \multirow{3}{*}{$\begin{array}{l}\text { Regular } \\
\text { workout }\end{array}$} & No & $49.65 \pm 7.82$ & & $32.65 \pm 4.67$ & & $22.82 \pm 5.76$ & \\
\hline & Sometimes & $44.14 \pm 11.20$ & & $34.35 \pm 4.61$ & & $22.57 \pm 3.63$ & \\
\hline & Yes & $47.60 \pm 9.54$ & $\begin{array}{l}.458 \\
(.633)\end{array}$ & $33.31 \pm 5.01$ & $\begin{array}{l}.413 \\
(.662)\end{array}$ & $24.80 \pm 6.05$ & $\begin{array}{l}2.298 \\
(.103)\end{array}$ \\
\hline \multirow[t]{2}{*}{ Regular diet } & No & $48.90 \pm 8.99$ & & $33.21 \pm 4.90$ & & $22.78 \pm 5.37$ & \\
\hline & Sometimes & $51.33 \pm 4.16$ & & $30.66 \pm 2.08$ & & $21.66 \pm 3.05$ & \\
\hline \multirow{3}{*}{$\begin{array}{l}\text { Economic } \\
\text { level }\end{array}$} & High & $52.19 \pm 11.18$ & $\begin{array}{l}2.159 \\
(.118)\end{array}$ & $33.00 \pm 4.63$ & $\begin{array}{l}1.185 \\
(.308)\end{array}$ & $22.95 \pm 7.56$ & $\begin{array}{l}.505 \\
(.604)\end{array}$ \\
\hline & Medium & $48.43 \pm 8.79$ & & $33.03 \pm 4.91$ & & $23.35 \pm 5.18$ & \\
\hline & Low & $46.55 \pm 7.80$ & & $34.88 \pm 4.86$ & & $22.00 \pm 5.94$ & \\
\hline
\end{tabular}

$* * \mathrm{p}<.01$

3.4. Relationships between perceived self-esteem, mental health, life satisfaction of nursing student's

Result of correlation test to identify each variable's independent influence over nursing student's mental health, self-esteem, and life satisfaction is as [Table4]. Nursing student's self-esteem had showed significant static correlation( $\mathrm{r}=.329, p<.01)$ with mental health.

[Table 4] Correlation of nursing student's perceived self-esteem, mental health, life satisfaction( $\mathrm{N}=195)$

\begin{tabular}{|l|l|l|l|}
\hline \multirow{2}{*}{ Variables } & Perceived Self-Esteem & Mental Health & Life Satisfaction \\
\cline { 2 - 4 } & $\mathbf{r}(\boldsymbol{p})$ & $\mathbf{r}(\boldsymbol{p})$ & $\mathbf{r}(\boldsymbol{p})$ \\
\hline Perceived Self-Esteem & 1 & & \\
\hline Mental Health & $-.610(<.01)$ & 1 & \\
\hline Life Satisfaction & $.329(<.01)$ & $-.165(<.05)$ & 1 \\
\hline
\end{tabular}




\subsection{Factors affecting nursing student's life satisfaction}

To identify influence factor of nursing student's life satisfaction, general characteristics variables showing differences in life satisfaction and correlative variables from correlation test is set as predictor variables to run multiple regression analysis. Nominal scale is analyzed with variable number processing, after verifying multi-collinearity with VIF and Dubin-Watson value, and correlation between residuals, stepwise multiple regression analysis was processed. As a result, influence factor to life satisfaction was admission motive, self-esteem as in order, and it explained $11.9 \%$ of life satisfaction of nursing students.

[Table 5-] Influential factors relevant to life satisfaction $(\mathrm{N}=195)$

\begin{tabular}{|c|c|c|c|c|c|}
\hline Variables & B & SE & $\beta$ & $\mathbf{t}$ & $p$ \\
\hline Constant & 7.961 & 5.022 & & 1.585 & $<.115$ \\
\hline Mental Health & .016 & .051 & .027 & .323 & $<.747$ \\
\hline Perceived Self-Esteem & .362 & .094 & .320 & 3.830 & $<.000$ \\
\hline Admission motive & 1.181 & .293 & .266 & 4.028 & $<.000$ \\
\hline
\end{tabular}

\section{DISCUSSION}

Nursing students have difficulties over career adaptation because of performing clinical practice while learning and relatively strict tradition and rules. According to Cater[15], female students majoring in nursing have more stress and adaptation problems over female students majoring in literature, and nursing students experience severe stress, anxiety, and dissatisfaction not only from nursing education course itself, but being near sick patients also be more stressful factor. Self-esteem and mental health could affect how to perceive, interpret, and deal with stress, It could act as a protective factor to evaluate self positively, altering life satisfaction which is an individual's physical, and mental adaptational result [16]. This study notable showed that the variables affecting nursing student's life satisfaction was mental health, self-esteem, and admission motives showing significant influence, thus nursing students being under the condition of doing both overburdening theoretic and clinical practice, repeated studies to promote nursing student's life satisfaction by identifying variables affecting their selfesteem and mental health, and developing education and program to promote their life satisfaction is necessary.

\section{CONCLUSION}

Considering mental health, and self-esteem which are identified to affect nursing student's life satisfaction, and developing life guidance program to actualize admission motive is necessary, and repeated study to promote life satisfaction of nursing student whose stress loads are more than other major is advised.

\section{REFRENCES:}

[1] Hwnag, H. W., A Research on Protective Factors Influencing on Adolescents' Quality of Life. Korea youth research association, vol. 18 No. 3, pp. 1-26. 2011.

[2] Kim, H.S., A Study on the Influence of University Students' Self Esteem And Social Support on the Life Satisfaction- Mediating
Effect of Adaptation to School Life- Unpublished masters thesis, Seonam University, 2014.

[3] Rosenberg, M., "Society and adolescent self-image". NJ : Princeton University Press. 1965

[4] Chung, H. J., Relationship of Family-of-origin Functioning with Self-differentiation and Psychological Well-being among College Students, Korean Association of Human Ecology, Vol. 17, No. 6, pp. 1135-1149. 2008.

[5] Lee, D. Y., Characteristics of Stress Response and Mental Health Status of University Students. Unpublished masters thesis, Daegu University, 2015

[6] Park, S. J., and Park, S. J., The Latent Classes of Adjustment to University and the Differeces of the Academic Plan of Freshmen. The Korean Educational Administration Society, Vol. 34, No. 2, pp. 75-95, 2016.

[7] Shim, J. S., Influence of Academic Self-efficacy, and Self-directed Learning Ability on Life Satisfaction of Nursing Students. The Journal of the Convergence on Culture Technology, Vol. 4, No. 2, pp. $17-25.2018$

[8] Heo, J. Y., Influences of childhood emotional trauma on mental health and life satisfaction of university students : Mediated by selfesteem. Unpublished masters thesis, Silla University, 2012.

[9] Lee, N. Y., The Mediating Effects of Self-Esteem in the relationship between Meaning in Life and Subjective Well-being in College Students, Unpublished masters thesis, Honhik University, 2013.

[10] Park, J. Y., Effect of Optimism and Self-esteem on Quality on Life of College Students. The Korean Association Rehabilitation Psychology, VoL. 24, No. 1, pp. 171-182, 2017

[11] Jeon, B. J., "Self-Esteem: A test of its measurability", Studies Yonsei, 11: 107-129, 1974

[12] Chang S. J., Health Statistics for Data Collection and Standardization of Measurement (translated by Nam W)., "The Korean Society for Preventive Medicine", Seoul, pp92-132, 2000.

[13] Dienner, E., Emmons, R. A., Larsen, R. J., \& Griffin, S., "The Satisfaction With Life Scale." Journal of Personality Assessment, Vol.49, pp. 71-75, 1985.

[14] Shim, Y. R., "A Validation Study of the Korean Version of the Calling and Vocation Questionnaire with a Korean College Student." Unpublished masters thesis, Ewha Womans University, 2010.

[15] Cater, E. W., Stress in the Nursing Students; Dispelling Some of the Myth. Nursing Outlook, April, 248-252, 1982.

[16] Choi, S. Y., Yoo, M. R., Lee, M. J., A Study on the Relationship Among Caders' Life Adjustment, Stress, Self-Esteem, and EgoResilience in Armed Forces Nursing Academy. Journal of military nursing research, 32(1), 1-13, 2014 